\title{
Implementation effects of economics and market operations based model for traditionally integrated power systems
}

\author{
Youssef Mobarak, Nithiyananthan Kannan, Fahd Alharbi, Faisal Albatati \\ Faculty of Engineering Rabigh, King Abdulaziz University, Jeddah, Saudi Arabia
}

\begin{abstract}
Article Info
Article history:

Received Sep 10, 2019

Revised Mar 17, 2020

Accepted Sep 7, 2020

\section{Keywords:}

Computing

Load management

Power demand

Power generation dispatch

Power generation economics

ABSTRACT

The main objective of this paper is to introduce power system economic operations in traditionally integrated power systems and market operations in deregulated power systems and study its effects. The power system economic operation is mathematically treated as an optimization problem. Also, a function of economic operation is to minimize generation cost, transmission losses, and so on, subject to power system operation constraints. In this paper, we start from generation cost formulations and introduce traditional economic dispatch model, optimal power flow model, and unit commitment model. With the deregulation of the power industry, integrated power system is unbundled to generation, transmission, and distribution. Electricity is traded in the wholesale market. Small customers purchase energy from electricity retailers through the retail market. The electricity market is operated for energy trading while satisfying power system operation requirements. Electricity market is mathematically modelled as an optimization problem that is subject to power system operation constraints and market operation constraints.
\end{abstract}

This is an open access article under the CC BY-SA license.

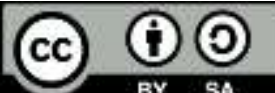

Corresponding Author:

Nithiyananthan Kannan

Departement of Electrical Engineering

King Abdul Aziz University, Rabigh branch

Rabigh Kingdom of Saudi Arabia

Email: nithiieee@yahoo.co.in

\section{INTRODUCTION}

In traditionally vertically integrated power systems, power companies are responsible for generation planning, transmission planning, generation scheduling, and system real-time operation [1-5]. Before late 1980s, computers were not widely applied in power system operations, and optimization technologies were not maturely developed for power system planning and operation [6-8]. Engineers use some straightforward methods to manually obtain suitable generation mixtures for the system, as well as to manually minimize the cost of generation scheduling [9-11]. Later, even after computer systems and various mathematic algorithms had been well developed for power system operations, the principle of generation planning and the way of generation scheduling, and dispatch were still based on the traditional methods [12-13]. Traditionally, each generating unit is assigned a certain number of operation hours per year. The number of annual operation hours depends on the type of the generating unit. For example, nuclear power is usually ON most of the time of the year except for maintenance. Its operation hours per year could be around 8,000 hours out of 8,760 hours per year. Large hydro power stations serving baseloads usually operate for 6,000-8,000 hours per year [14-15]. For coal-fired power plants, the annual operation hours are around 5,000-7,000 hours. Oil-fired and combined-cycle units are around 2,000-4,000 hours, depending on the available generation sources in the 
system. Wind power is subject to wind resources, its annual operation hour is around 2,000 hours electricity load has its cycle [16-17].

The marginal cost has been commonly used to price the value of the commodity in a market. In a traditional economic dispatch, system marginal cost determines the optimal operation points for generators, as well as the system marginal price. For a generator, the marginal cost (or incremental cost) function is the first derivative of its generation cost function to generate output. If transmission losses are ignored and there is no transmission congestion, an optimized generation schedule results in an equal marginal cost for each generator [18-19]. We will use several examples to illustrate how to clear the spot market and how to obtain locational marginal prices.

This part presents electricity market concepts and industry trends, also electricity market equilibrium, and characteristic of electricity. A market is a plane where producers and consumers of a product meet to make deals. Quantity of the product, price of the product, quality of the product. The main aim of the market is to bring down the production cost as low as possible and improve tariff to the customers and also to improve efficiency. The proposed research work will have impacts on consumer demand, supply on producer side and market equilibrium of the electricity as shown in Figure 1 [20-27].

Global Welfare is the sum of the consumer surplus and the producer profit it quantifies the benefit that arises from trading in Figure 2. External intervention redistributes the Global Welfare in favor of the producers the consumers or the government. Intervention examples are fixing a minimum or a maximum price, taxes and subventions. For a given hour, generator bids can be stacked in ascending order to form the system supply. Coal-fired steam power plants: provide more than half of the electric energy in the world. It can use any heat source to boil water and convert the rotational energy motion to electric energy. The efficiency of a thermal power plant is usually evaluated using heat rate.

$$
\eta=\frac{\text { Output }(k W h)}{\operatorname{Input}(k W h)}=\frac{\text { Output }(k W h)}{\left(\operatorname{Input}(k J) / 3600\left(\frac{\mathrm{Kj}}{\mathrm{kWh}}\right)\right)}
$$

Heat rate can be expressed using efficiency $\eta$.

$$
\text { Heat rate }(\mathrm{kJ} / \mathrm{kWh})=\frac{3,600\left(\frac{\mathrm{Kj}}{\mathrm{kWh}}\right)}{\eta}
$$

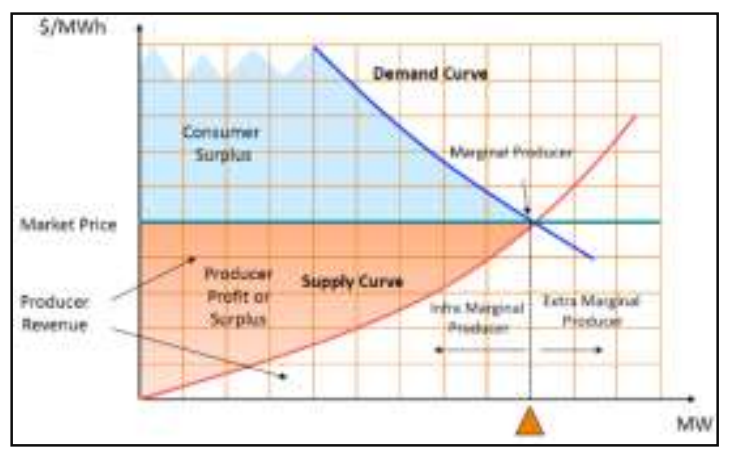

Figure 1. Electricity market equilibrium

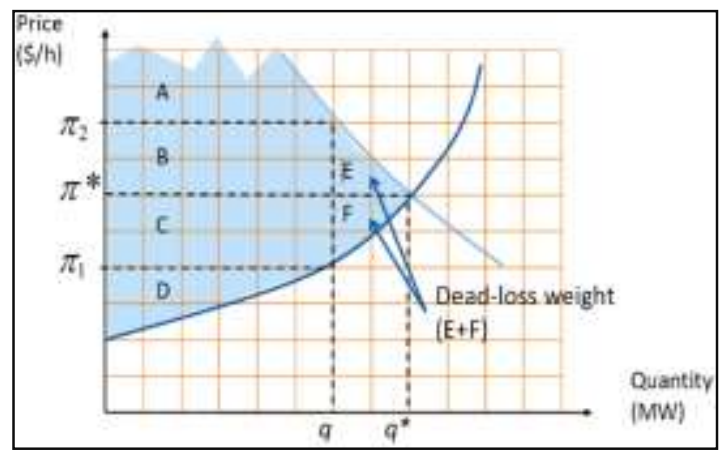

Figure 2. Global welfare

\section{POWER GENERATION COSTS}

The composed of generation system composed are boiler, turbine, and generator is not a linear system. Heat rates/coal rates differ at different output levels. Temperatures and other factors of the boiler also affect coal consumptions. In power system economic operation, fuel consumption of a coal-fired generating unit is usually considered as a quadratic function of power output. The function can be obtained with measurement data through curve fitting. The fuel (coal) consumption of a generating unit can be expressed by:

$$
F=a P^{2}+b P+c
$$

where: $\mathrm{F}$ is the amount of fuel consumed, $\mathrm{P}$ is the power output of the generating unit, and $\mathrm{a}, \mathrm{b}$, and $\mathrm{c}$ are coefficients. 
To assess the cost of electricity generation from a power plant, both fixed cost and variable cost need to be considered. Fixed costs are the expenses no matter the power plant is on or off. Variable costs are mostly fuel costs and operation costs. They are related to the amount of generated electricity. Depending on different types of generations, fixed costs and variable costs are quite different. If screening curves are used together with the system annual load duration curve, the optimal mix of various generators and their capacities can be obtained for generation planning. Electricity demand has its own cycle; the rearranged load curve is the load duration curve of the day. If we draw the operation hours of the three types of generators for a 24-hour period are on a chronological daily load curve, as shown in Figure 3. It shows that the hydro power operates most of the time during the day except a few hours in the night. The gas turbine supplies only peak loads during morning peak and afternoon peak hours. The capital cost of a gas-fired power plant is much lower compared to that of a coal-fired power plant, natural gas is more environmental friendly than coal, the carbon dioxide produced by a gas-fired power plant is around half of that produced by a coal-fired power plant in Figure 4.

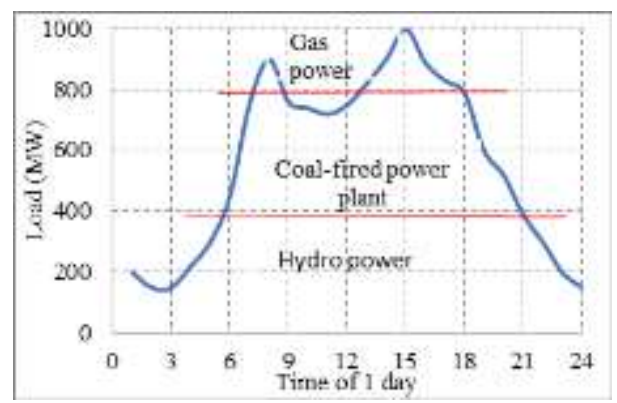

Figure 3. Daily load curve

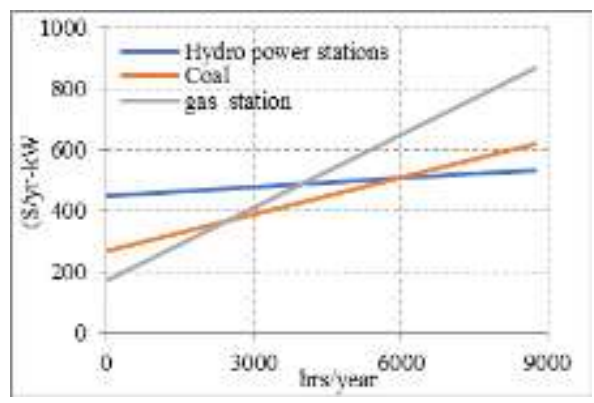

Figure 4. Coal equivalent consumption

\section{THE PROBLEM OF ECONOMIC DISPATCH}

Conventionally, fuel cost is the major concern of dispatching a generating unit. Units with less fuel costs are dispatched to generate more electricity. This simple economic principle is straightforward for generation dispatch; however, it is hard to be implemented accordingly due to nonlinear characteristics of power generations. Fuel consumptions and generation outputs are not in a linear relationship. To obtain the most economical solution for generation dispatch, optimization model is needed for the dispatch problem. In this section, we will introduce the principle and the mathematical model of generation economic dispatch, as well as its solution methods. The solution of economic dispatch is to find a generation schedule for power balance between power suppliers (generators) and demand (customers), just like any other commodities. For generation dispatch. The objective is to find the power generation schedule $P_{G i}$ for each generating unit $i$, and the solution is the most economic one. The generation cost is a nonlinear function of power output. Here, a quadratic function is used to represent the cost function of generating unit $i$.

$$
C i\left(P_{G i}\right)=a P_{G i}^{2}+b P_{G i}+c
$$

Where: $C_{i}\left(\mathrm{P}_{\mathrm{Gi}}\right)$ is the generation cost function of unit $i$, and $a, b$, and $c$ are coefficients. The objective of generation economic dispatch is to minimize the total generation cost $C_{\text {total, }}$ which is the sum of the costs of all generating units. The objective function can be expressed as:

$$
\operatorname{Min} C_{\text {Total }} \sum_{i=1}^{N} \operatorname{Ci}\left(P_{G i}\right)=\sum_{i=1}^{N} P_{G i}=P_{\text {Load }}
$$

The power balance (5) ignores transmission network and losses. $\mathrm{P}_{\text {Load }}$ is the total system load, due to turbine design.

$$
\phi=P_{L o a d}-\sum_{i=1}^{N} P_{G i}
$$

The Lagrange function $L$ is to add the constraint function $\phi$ multiplied by an undetermined multiplier $\lambda$ to the objective function $\mathrm{C}_{\text {Total }}$ as:

$$
L=C_{\text {Total }}+\lambda \phi=\sum_{i=1}^{N} \operatorname{Ci}\left(P_{G i}\right)+\lambda\left(P_{\text {Load }}-\sum_{i=1}^{N} P_{G i}\right)
$$


$L=\sum_{i=1}^{N}\left(C i\left(P_{G i}\right)-\lambda P_{G i}\right)+\lambda P_{\text {Load }}$

For each independent variable $P_{G i}$ and $\lambda$, we have:

$$
\frac{\partial L}{\partial P_{G i}}=\frac{d C i\left(P_{G i}\right)}{d P_{G i}}-\lambda=0
$$

And $\quad \frac{\partial L}{\partial \lambda}=-\sum_{i=1}^{N} P_{G i}+P_{\text {Load }}=0$

With inequality constraints, the necessary conditions for an optimum can be found based on the complimentary slackness condition of KKT conditions.

$$
\begin{aligned}
& \frac{d C_{i}\left(P_{G i}\right)}{d P_{G i}}=\lambda, \text { for } P_{G i}^{\min }<P_{G i}<P_{G i}^{\max } \\
& \frac{d C_{i}\left(P_{G i}\right)}{d P_{G i}} d \leq \lambda, \text { for } P_{G i}=P_{G i}^{\max } \\
& \frac{d C_{i}\left(P_{G i}\right)}{d P_{G i}} d \geq \lambda, \text { for } P_{G i}=P_{G i}^{\min }
\end{aligned}
$$

\subsection{Case study}

There are four generators in the system. Generator 1, 2, and 3 are coal-fired generators and generator 4 is a gas turbine. Their fuel consumption functions are given as follows:

$$
\begin{aligned}
& F\left(P_{G 1}\right)=0.148 P_{G 1}^{2}+199.4 P_{G 1}+16425 \\
& F\left(P_{G 2}\right)=0.024 P_{G 2}^{2}+252.7 P_{G 2}+16686 \\
& F\left(P_{G 3}\right)=0.136 P_{G 3}^{2}+206.3 P_{G 3}+15433 \\
& F\left(P_{G 4}\right)=0.109 P_{G 4}^{2}+168.0 P_{G 4}+16639
\end{aligned}
$$

To find optimal generation schedule using economic dispatch neglecting losses if the system total load is $1,500 \mathrm{MW}$. Also, if the cost of fuel (coal equivalent) of generator 4 is 1.25 times of the fuel cost of other coal-fired generators. If the total cost and system incremental cost given the coal price is $\$ 80 /$ tce (tce is ton of coal equivalent). Incremental fuel consumption functions for the generators. This is the optimal generation dispatch results. Generators 2 and 4 consume relatively less fuels, so their generation outputs are higher in the economic dispatch result. We assume that the coal price for coal-fired generators is $\rho$ (in $\$ / \mathrm{kg}$ ). If the fuel cost of generator 4 is 1.25 times that of other coal-fired generators, its fuel price is $1.25 \rho$ (in $\$ / \mathrm{kg}$ ).

The incremental coal consumption is $284.16 \mathrm{~kg} / \mathrm{MWh}$, and the incremental cost is $284.16 \mathrm{~kg} / \mathrm{MWh}$ times coal price $\rho$. Then, generation schedules for four generators are. The solutions show that the generation output of generator 4 is reduced due to its higher fuel cost. Other generators need to generate more electricity at a higher coal rate. Given coal price as $\rho=0.08 \$ / \mathrm{kg}$, then $\lambda=22.73 \$ / \mathrm{MWh}$. The total fuel cost is $36,152 \$$ to generate $1,500 \mathrm{MW}$ within 1 hour. The average cost is $36,152 \$ / 1,500 \mathrm{MWh}=24 \$ / \mathrm{MWh}$ as shown in Table 1 . First, the optimal solution without considering generation limits can be obtained. We find that generations from generators 1,2 , and 3 are within the limits, while the generation of generator 4 is higher than its upper generation limit. So, we set the generation output of generator 4 as $400 \mathrm{MW}$, which is its upper limit, then dispatch the remaining demand requirement $(1,500 \mathrm{MW}-400 \mathrm{MW}=1,100 \mathrm{MW})$ among the rest three generators. As generator 4 reaches its upper limit $400 \mathrm{MW}$, while other generators need to generate more to satisfy the system load requirement. The incremental fuel consumption for generators 1, 2, and 3 with economic dispatch in this case studied is $279.58 \mathrm{~kg} / \mathrm{MWh}$. It is a little bit higher than the incremental fuel consumption $276.1 \mathrm{~kg} / \mathrm{MWh}$. The reason is that generator 4 reaches its upper generation limit. Other generators need to generate at higher output levels with higher incremental fuel consumptions, as shown in Table 2 .

Table 1. Generation schedule without constraint

\begin{tabular}{cccccc}
\hline Generators & $\mathrm{P}_{\mathrm{G} 1}$ & $\mathrm{P}_{\mathrm{G} 2}$ & $\mathrm{P}_{\mathrm{G} 3}$ & $\mathrm{P}_{\mathrm{G} 4}$ & Total \\
\hline Generation MW) & 259.0 & 487.4 & 256.5 & 495.9 & 1500 \\
Cost $(\$)$ & 6.24 & 11.64 & 6.18 & 12.67 & 36.74 \\
Generation MW) & 286.2 & 655.3 & 286.3 & 272.2 & 1500 \\
Cost $(\$)$ & 6.85 & 15.4 & 6.85 & 7.04 & 36.15 \\
\hline
\end{tabular}

Table.2. Generation schedule with constraint

\begin{tabular}{cccccc}
\hline Generators & $\mathrm{P}_{\mathrm{G} 1}$ & $\mathrm{P}_{\mathrm{G} 2}$ & $\mathrm{P}_{\mathrm{G} 3}$ & $\mathrm{P}_{\mathrm{G} 4}$ & Total \\
\hline Generation MW) & 259.0 & 487.4 & 256.5 & 495.9 & 1500 \\
Generation MW) & 270.8 & 559.9 & 269.3 & 400.0 & 1500 \\
Cost (\$) & 6.502 & 13.255 & 6.468 & 10.127 & 36.354 \\
\hline
\end{tabular}




\section{UNIT COMMITMENT}

This problem is unit commitment UC is an optimization process where the system operator choses the production units states (on-off) and their production level in order to minimize the production costs (system price or social welfare) and to meet demand, through a period of time (a day ahead or week ahead) subject to start and stop times, ramp rates and operational limits constraints of each production unit. In this section, we will use an studied case to explain the principles of unit commitment. Then, the mathematic model of unit commitment is presented and discussed. We first use an illustrative studied system to describe the basic concept of UC. Transmission network and losses are ignored in the studied for simplicity. Assume there are three generators in the system as shown in the following equations:

$$
\begin{aligned}
& F\left(P_{G 1}\right)=0.148 P_{G 1}^{2}+199.4 P_{G 1}+16425 \\
& F\left(P_{G 2}\right)=0.024 P_{G 2}^{2}+252.7 P_{G 2}+16686 \\
& F\left(P_{G 3}\right)=0.109 P_{G 3}^{2}+168.0 P_{G 3}+16639
\end{aligned}
$$

$$
150 M W \leq P_{G 1} \leq 300 M W, 300 M W \leq P_{G 2} \leq 600 \text {, and } 250 M W \leq P_{G 3} \leq 400
$$

In this case, to simplify the calculation procedure, we select three generators. To supply the load in the system, there are seven options $\left(2^{3}-1\right)$ to combine the three generators, which are shown in the following Table 3. For a load of $500 \mathrm{MW}$, options 1 and 3 do not have enough capacity to supply the load. The maximum outputs of generator 1 and generator 3 are lower than the load, $500 \mathrm{MW}$. Options 2, 4-7 are feasible solutions to supply the load. The next question is which option is the best solution. As the generators that are $\mathrm{ON}$ in each option is given, we can use economic dispatch ED or optimal power flow OPF to obtain the least-cost generation schedule for each option.

In this studied case illustrative, transmission network is ignored. According to the results obtained in the tables, the best (optimal) UC options are summarized for different load levels and listed in Table 4. From the table, a priority list is obtained for generators with the increase in load. The priority list is (1) generator 3; (2) generators 1 and 3; (3) generators 2 and 3; (4) generators 1, 2, and 3. There are two peak load periods, one is in the morning before noon time and the other one is in the afternoon, the loads in the night is low. The Table 5 shows that generator 3 is always ON for the whole day. Generator 1 is switched on at 4 a.m. in the morning when the load increases. With further increase in load, generator 1 reaches its limit and swaps with generator 2, generator 2 is $\mathrm{ON}$. When the load reaches the peak value, 1,300 MW, all three is ON.

Table 3. Generation schedule with constraint

\begin{tabular}{cccccccc}
\hline options & 1 & 2 & 3 & 4 & 5 & 6 & 7 \\
\hline Generator 1 & ON & - & - & ON & ON & - & ON \\
Generator 2 & - & ON & - & ON & - & ON & ON \\
Generator 3 & - & - & ON & - & ON & ON & ON \\
Max. output (MW) & 300 & 600 & 400 & 900 & 700 & 1000 & 1300 \\
\hline
\end{tabular}

Table 4. Unit commitment and generation schedule results for different load levels

\begin{tabular}{ccccccccc}
\hline Load, MW & 400 & 500 & 600 & 700 & 800 & 900 & 1,000 & 1,100 \\
\hline Gen. 1 & - & 151 & 200 & 300 & - & - & - & 252.6 \\
Gen. 2 & - & - & - & - & 400 & 500 & 600 & 447.4 \\
Gen. 3 & 400 & 349 & 400 & 400 & 400 & 400 & 400 & 400 \\
Consumption, kg & 101,279 & 138,456 & 163,504 & 190,844 & 222,885 & 250,315 & 278,225 & 312,064 \\
\hline
\end{tabular}

Table 5. Unit commitment result for 24 hours

\begin{tabular}{ccccccccccccc}
\hline Hour & 1 & 2 & 3 & 4 & 5 & 6 & 7 & 8 & 9 & 10 & 11 & 12 \\
\hline Load & 500 & 400 & 400 & 500 & 500 & 600 & 700 & 800 & 900 & 1,000 & 1,100 & 1,000 \\
Generator 1 & ON & - & - & ON & ON & ON & ON & - & - & - & ON & ON \\
Generator 2 & - & - & - & - & - & - & - & ON & ON & ON & ON & ON \\
Generator 3 & ON & ON & ON & ON & ON & ON & ON & ON & ON & ON & ON & ON \\
\hline
\end{tabular}

\begin{tabular}{ccccccccccccc}
\hline Hour & 13 & 14 & 15 & 16 & 17 & 18 & 19 & 20 & 21 & 22 & 23 & 24 \\
\hline Load & 900 & 900 & 1,000 & 1,000 & 900 & 900 & 800 & 800 & 700 & 700 & 600 & 500 \\
Generator 1 & - & - & - & - & - & - & - & - & ON & ON & ON & ON \\
Generator 2 & ON & ON & ON & ON & ON & ON & ON & ON & - & - & - & - \\
Generator 3 & ON & ON & ON & ON & ON & ON & ON & ON & ON & ON & ON & ON \\
\hline
\end{tabular}




\section{ELECTRICITY MARKET PRICING MODELS}

We will introduce market clearing mechanisms for both nodal price-based market and zonal pricebased market. To illustrate the electricity market clearing for a nodal price-based market, we will present the market model mathematically with an optimization problem. The optimization problem is solved to obtain locational marginal price LMP, which is the marginal price at each node.

Nodal price-based market model: Due to line impedances and transmission limits, the costeffectiveness of demand changes on each node is different. So, the marginal cost is calculated for each node individually, which is a node/location based marginal cost. In an electricity market, cost functions are confidential information for generation companies. Marginal price of the market is calculated according to locations. It is called the locational marginal price LMP, which is a nodal price. The locational marginal price is obtained by solving the optimal power flow OPF-based market model. Optimal power flow-based market model: The objective function of the market model is to maximize the market benefit. In other words, it is to maximize the amount paid by buyers/customers and minimize the amount paid to sellers/generators. So, the buyers with higher bids and sellers with lower offers are selected. The objective function is formulated as:

$$
\text { Min. Benefit }=\sum_{\mathrm{i}=1}^{\mathrm{N}} \mathrm{B}_{\mathrm{i}} \mathrm{P}_{\mathrm{Di}}-\sum_{\mathrm{i}=1}^{\mathrm{N}} \mathrm{S}_{\mathrm{i}} \mathrm{P}_{\mathrm{Gi}}
$$

Where: $\mathrm{B}_{\mathrm{i}} \mathrm{P}_{\mathrm{Di}}$ is the aggregated demand curve constituted by bid price-quantity pairs submitted by buyers, and $\mathrm{S}_{\mathrm{i}} \mathrm{P}_{\mathrm{Gi}}$ is the aggregated supply curve constituted by the offer price-quantity pairs submitted by sellers. It is assumed that electricity demand is elastic demand in the market. Buyers' bids change at different load levels. However, in some cases, buyers' bids are inelastic. Then, the objective function can be formulated as follows:

$$
\text { Min. Payment }=\sum_{\mathrm{i}=1}^{\mathrm{N}} \mathrm{S}_{\mathrm{i}} \mathrm{P}_{\mathrm{Gi}}
$$

We will use (20) and (21) as objective functions of the market model to study market clearing and the characteristics of locational marginal prices. The market model of this studied case can be written as follows:

$$
\text { Min. Payment }=\sum_{\mathrm{i}=1}^{3} \mathrm{~S}_{\mathrm{i}}\left(\mathrm{P}_{\mathrm{Gi}}\right)=10 \mathrm{P}_{\mathrm{G} 1}+20 \mathrm{P}_{\mathrm{G} 2}
$$

The topology of a three-node power system is resistance of each line is ignored, which means there is no loss considered. There are two generators located at node 1 and node 2 , respectively. The capacity of the generator at node $1, \mathrm{G}_{1}$, is $300 \mathrm{MW}$, and its offer price is $10 \$ / \mathrm{MWh}$. The capacity of the generator at node 2 , $\mathrm{G}_{2}$ is $200 \mathrm{MW}$, and its offer price is $20 \$ / \mathrm{MWh}$. The total load is $300 \mathrm{MW}$ on node 2 and node 3 , where $\mathrm{P}_{\mathrm{D} 2}=50 \mathrm{MW}$, and $\mathrm{P}_{\mathrm{D} 3}=250 \mathrm{MW}$. The objective function of a model is a two-segment function. Using the Lagrange function, the optimal solution for the model can be easily obtained as $\mathrm{P}_{\mathrm{G} 1}=3$ (per unit), $\mathrm{P}_{\mathrm{G} 2}=0$. The price of $10 \$ / \mathrm{MWh}$ is, in fact, the energy component of LMP, as there is no loss or congestion in the market. The total payment to Generator 1 is $3000 \$$ for 1 hour. Without considering the network effect of losses and congestions, the market model is quite simple. It can be formulated as follows:

$$
\text { Min. Payment }=\sum_{\mathrm{i}=1}^{\mathrm{N}} \mathrm{S}_{\mathrm{i}} \mathrm{P}_{\mathrm{Gi}}=12 \mathrm{P}_{\mathrm{G} 1}+15 \mathrm{P}_{\mathrm{G} 2}+20 \mathrm{P}_{\mathrm{G} 3}
$$

The market model has a discontinuous objective function due to the piecewise payment function. The optimality can be obtained for each section. The marginal price is $\lambda$, which is formulated as:

$$
\lambda=\left\{\begin{array}{c}
120<\mathrm{P}_{\mathrm{D}}<300 \\
15300<\mathrm{P}_{\mathrm{D}}<450 \\
20450<\mathrm{P}_{\mathrm{D}}<650
\end{array}\right.
$$

As network effect is not considered, there is no difference identified for the locations of three generators. LMP is the same for all generators, and equal to $\lambda$. In fact, this is the energy component, as no loss or congestion component is counted. If the load is $400 \mathrm{MW}$, it falls in the second section, the marginal price is $15 \$ / \mathrm{MWh}$ for selected two generators: Generator 1 and Generator 2. Generator 3 is not selected due to its high offer price. If the load is $500 \mathrm{MW}$, the demand falls in the third section, the marginal price is 20\$/MWh for three generators, which are all selected by the market. 


\subsection{Without loss or congestions at $L=300 M W$}

The capacity of the generator at node $1, \mathrm{G}_{1}$, is $300 \mathrm{MW}$, and its offer price is $10 \$ / \mathrm{MWh}$. The capacity of the generator at node $2, \mathrm{G}_{2}$ is $200 \mathrm{MW}$, and its offer price is $20 \$ / \mathrm{MWh}$. The total load is $300 \mathrm{MW}$ on node 2 and node 3 , where $\mathrm{P}_{\mathrm{D} 1}=50 \mathrm{MW}$ and $\mathrm{P}_{\mathrm{D} 2}=250 \mathrm{MW}$. Assuming that transmission line limits are not constrained, no congestion. The market model of this case can be written as follows:

$$
\text { Min. Payment }=\sum_{\mathrm{i}=1}^{\mathrm{N}} \mathrm{S}_{\mathrm{i}} \mathrm{P}_{\mathrm{Gi}}=10 \mathrm{P}_{\mathrm{G} 1}+20 \mathrm{P}_{\mathrm{G} 2}
$$

We have: $\mathrm{P}_{\mathrm{G} 1}=300 \mathrm{MW}, \mathrm{P}_{\mathrm{G} 2}=0, \mathrm{LMP}_{1}=\mathrm{LMP}_{2}=\mathrm{LMP}_{3}=10 \$ / \mathrm{MWh}$. The price of $\$ 10 / \mathrm{MWh}$ is, in fact, the energy component of $\mathrm{LMP}_{\mathrm{s}}$, as there is no loss or congestion in the market. The total payment to Generator 1 is $3000 \$$. Load at node 2 needs to pay $500 \$$ and load at node 3 needs to pay 2500\$. The total load payment at node 2, 3 are $3000 \$$ as shown in Figure 5(a).

\subsection{Without loss or congestions at $L=400 M W$}

We continue to test the market model and assume that the load is increased to $400 \mathrm{MW}$, with $\mathrm{P}_{\mathrm{D} 2}=50 \mathrm{MW}$, and $\mathrm{P}_{\mathrm{D} 3}=350 \mathrm{MW}$. Rewriting the model, we can optimize the model for Load=400MW or $4 \mathrm{pu}$. Using the similar method, the model is solved, and the solution are as follows:

$$
\begin{aligned}
\mathrm{P}_{12} & =40 \mathrm{MW}, \quad \mathrm{P}_{13}=260 \mathrm{MW} \text { and } \mathrm{P}_{23}=90 \mathrm{MW}, \mathrm{P}_{\mathrm{G} 1}=300 \mathrm{MW}, \mathrm{P}_{\mathrm{G} 2}=100 \mathrm{MW}, \\
\mathrm{LMP}_{1}=\mathrm{LMP}_{2} & =\mathrm{LMP}_{3}=20 \$ / \mathrm{MWh}
\end{aligned}
$$

Load at node 2 needs to pay 1000\$, and load at node 3 needs to pay $7000 \$$. The total load payment at node 2, 3 are 8000\$, as shown in Figure 5(b).

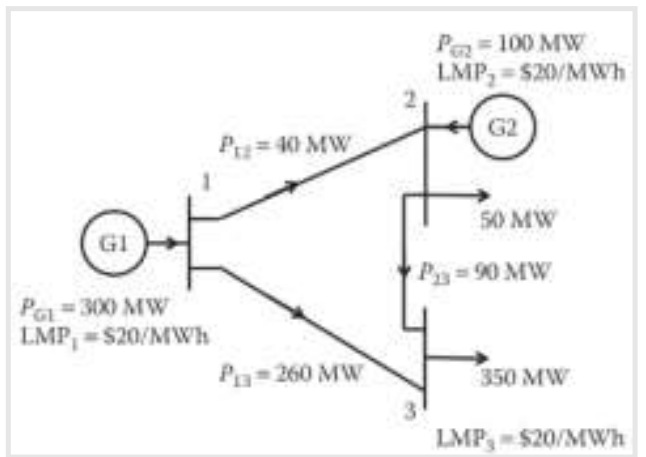

(a) $\mathrm{Load}=300 \mathrm{MW}$

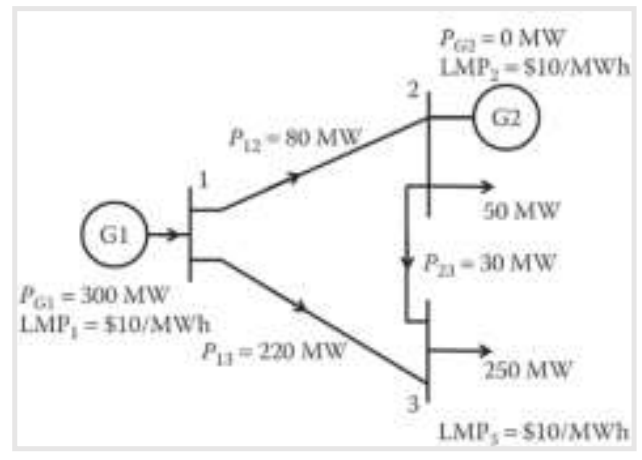

(b) $\mathrm{Load}=400 \mathrm{MW}$

Figure 5. Without loss or congestion

\subsection{With congestions at $\mathrm{L}=300 \mathrm{MW}$}

In this case, we continue assume the line between node 1 and 3 has a transmission limit $\mathrm{P}_{13 \max }=200 \mathrm{MW}$ value of the transmission limit. The market optimization model for this case, the objective function and other constraints are the same. By substituting the value of $\mathrm{X}_{13}=1$, and $\mathrm{P}_{13} \max =2 \mathrm{pu}$. The constraint is formulated as the following model:

$$
\text { Min. Payment }=10 \mathrm{P}_{\mathrm{G} 1}+20 \mathrm{P}_{\mathrm{G} 2}
$$

The necessary conditions for an optimal solution are that the derivatives of the Lagrange function with respect to control variables and state variables are equal to zero. By solving the previous five equations, we can obtain $\lambda_{1}=10 \$ / \mathrm{MWh}, \lambda_{2}=20 \$ / \mathrm{MWh}, \lambda_{3}=30 \$ / \mathrm{MWh}$, and $\mu_{13}=25 \$ / \mathrm{MWh}$. The optimal solution for power generation is $\mathrm{P}_{\mathrm{G} 1}=250 \mathrm{MW}, \mathrm{P}_{\mathrm{G} 2}=50 \mathrm{MW}, \mathrm{P}_{12}=50 \mathrm{MW}, \mathrm{P}_{13}=200 \mathrm{MW}$, and $\mathrm{P}_{23}=50 \mathrm{MW}$. Load at node 2 needs to pay $1000 \$$, and load at node 3 needs to pay $7500 \$$. At $\mathrm{L}=300 \mathrm{MW}$, the total load payment at node $2 \& 3=8500 \$ / \mathrm{hr}$. The results show that locational marginal prices for three nodes become different due to the congestion between node 1 and node 3 . The $\mathrm{LMP}_{\mathrm{s}}$ are $\mathrm{LMP}_{1}=10 \$ / \mathrm{MWh}, \mathrm{LMP}_{2}=20 \$ / \mathrm{MWh}$, and $\mathrm{LMP}_{3}=30 \$ / \mathrm{MWh}$. Due to the transmission limit and congestion between node 1 and 3 , we notice that the optimal generation schedule and $\mathrm{LMP}_{\mathrm{s}}$ have a big difference compared to the results of studied case without loss or congestion, which has no transmission limit. The less expensive generator, Generator 1, is not 
dispatched to generate at its full capacity due to the transmission ability of line $1-3$. Generator 1 generates $250 \mathrm{MW}$, and the remaining $50 \mathrm{MW}$ is generated by the expensive Generator 2. Power flow is redistributed according to line impedances. Without transmission congestion, $\mathrm{LMP}_{\mathrm{s}}$ for all node are the same and equal to $10 \$ / \mathrm{MWh}$ as shown in Figure 6(a).

\subsection{With congestions at $\mathrm{L}=310 \mathrm{MW}$}

This case to verify the locational marginal price obtained, we increase $\mathrm{P}_{\mathrm{D}}=310 \mathrm{MW}$, and calculate the incremental payment due to the load increase. $\lambda_{1}=10 \$ / \mathrm{MWh}, \lambda_{2}=20 \$ / \mathrm{MWh}, \lambda_{3}=30 \$ / \mathrm{MWh}$. $\mathrm{P}_{\mathrm{G} 1}=240 \mathrm{MW}$, $\mathrm{P}_{\mathrm{G} 2}=70 \mathrm{MW}$, and $\mathrm{P}_{12}=40 \mathrm{MW}, \mathrm{P}_{13}=200 \mathrm{MW}$, and $\mathrm{P}_{23}=60 \mathrm{MW}$. Load at node 2 needs to pay $1000 \$$, and load at node 3 needs to pay $7800 \$$. At $\mathrm{L}=310 \mathrm{MW}$, the total load payment at node $2 \& 3=8800 \$ / \mathrm{hr}$. However, with congestions, $\mathrm{LMP}_{1}=10 \$ / \mathrm{MWh}, \mathrm{LMP}_{2}=20 \$ / \mathrm{MWh}$, and $\mathrm{LMP}_{3}=30 \$ / \mathrm{MWh}$. This means that customers at node 2 and node 3 will need to pay. Load at node 2 needs to pay $1000 \$$, and load at node 3 needs to pay $7500 \$$. Both loads need to pay much higher than the case in without loss or congestion. The total payment from loads is $8500 \$$. At the generation side, Generator 1 is paid by $2500 \$$ and Generator 2 is paid by $1000 \$$. The total amount received by generators is $3500 \$$. The difference between the amount paid by loads and the amount received by the generators is the congestion cost, which is $5000 \$$. From this case, it is shown that the congestion cost could be very high, and the risk of congestion (or delivery risk) is high in an electricity market. The methods to hedge congestion risk are necessary for an electricity market as shown in Figure 6(b).

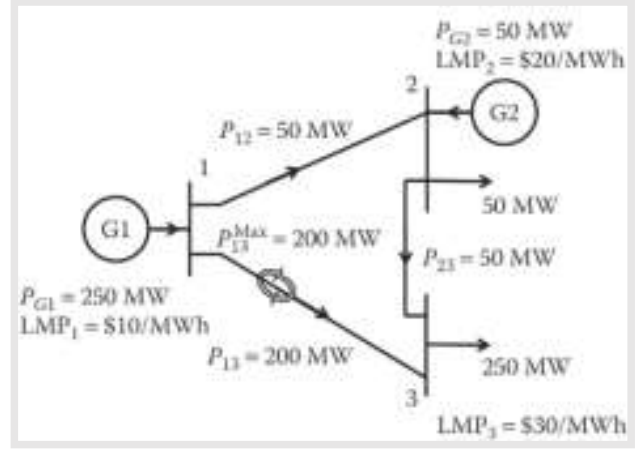

(a) $\mathrm{Load}=300 \mathrm{MW}$

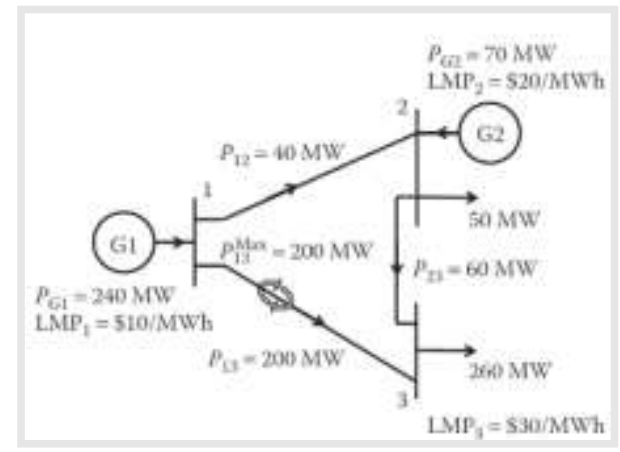

(b) $\mathrm{Load}=310 \mathrm{MW}$

Figure 6. With loss or congestion

\section{CONCLUSIONS}

There is different type of fuel to generate the electricity on the world some of the low fuel cost and high build cost and the vice versa. The most fears of the power system planning, and scheduling is the costs of generations. Because it's coupled with various factors. It has a different fixed costs and variable costs. The screening curves can help to generation planning for a long time according to forecasted load pattern of the system. Economic dispatch has been commonly used in power systems since a long time. The equal incremental cost method and the coordination equation are efficient in procuring optimized generation schedules.Optimal power flow is a more complicated version of economic dispatch by considering full network model using power flow equations. Unit commitment problem is a multiple time period optimization problem that optimizes the total operation cost and all start-up costs within a long time period. By making generation unit commitment schedules. The minimization of operation cost and start-up cost must be done for the whole time period to obtain generation schedules. From the market model solutions, we found that for a market without congestion, and without considering losses, the locational marginal price for each node is the same, and all are equal to the offer price of the marginal generator. The LMP $\mathrm{s}_{\mathrm{s}}$ obtained in without considering losses are the energy components of locational marginal prices.

\section{REFERENCES}

[1] Future of energy, "Presented at the Fourth Annual National Democratic Party Congress," Cairo, Sept. 2005, Egypt's State Information System (SIS), 2005.

[2] D. Loy, "Energy policy framework conditions for electricity market and renewable energies," Country analyses, chapter Egypt, GTZ, GmbH, 2007. 
[3] H. El Nokaschy, Renewable energy mix for Egypt, Nokraschy Engineering GmbH, 2007.

[4] C. Philiber, "The present and future use of solar thermal energy as a primary source of energy," International Energy Agency, Paris, France, 2005.

[5] K. Ummel, D. Wheeler, "Desert power - The economics of solar thermal energy in Europe, North Africa and the Middle East," Center for Global Development, 2008.

[6] A.M. El-Zalabany, "The first thermal solar power plant in Egypt," Presented at the solar thermal power and desalination symposium, Cairo, 2007.

[7] H. El Nokaschy, "Renewable energies around the Mediterranean," Nokraschy Engineering, 2008. Trans-Mediterranean Renewable Energy Cooperation: DESERTEC concept for energy, water and climate security in EU-MENA, 2007.

[8] R. Kumar, A. Sadu, R. Kumar, and S.K. Panda, "A Novel multi-objective bee colony optimization algorithm for multi-objective emission constrained economic power dispatch," Electrical Power and Energy Systems, vol. 43 pp.1241-1250, 2012.

[9] M. Hong, K. Sperry, J. Williams and J. Gardner, "Electricity market and operations reliability," 2012 IEEE Power and Energy Society General Meeting, San Diego, CA, pp. 1-7, 2012. doi: 10.1109/PESGM.2012.6344765.

[10] M.I. lanco, "The economics of wind energy," Renewable and Sustainable Energy Reviews, vol. 13, no. 6-7, pp. 1372-1382, 2009.

[11] Ralon, Pablo, et al., "Electricity storage and renewables: Costs and markets to 2030," International Renewable Energy Agency, Abu Dhabi, 2017.

[12] M. Bestha, K. H. Reddy and O. Hemakeshavulu, "Economic Load Dispatch Downside with Valve - Point Result Employing a Binary Bat Formula," International Journal of Electrical and Computer Engineering, vol 4, no. 1, pp. 101-107, 2014.

[13] A. I. Selvakumar and K. Thanushkodi, "A New Particle Swarm Optimization Solution to Nonconvex Economic Dispatch Problems," in IEEE Transactions on Power Systems, vol. 22, no. 1, pp. 42-51, 2007, doi: 10.1109/TPWRS.2006.889132.

[14] B. Mahdad and K. Srairi, "Interactive gravitational search algorithm and pattern search algorithms for practical Dynamic Economic Dispatch," International Transactions on Electrical Energy System, vol. 25, no. 10, pp. 2289$2309,2014$.

[15] W. Khamsen, et al., "Hybrid method for solving the nonsmooth cost function economic dispatch problem," International Journal of Electrical and Computer Engineering, vol. 10, no. 1, pp. 609-616, 2020

[16] S. Fadil and B. Urazel, "Solution to security constrained non convex pumped-storage hydraulic unit scheduling problem by modified sub-gradient algorithm based on feasible values and pseudo water price," Electric Power Components and Systems, vol. 41, no. 2, pp. 111-135, 2013

[17] I. A. Farhat and M. E. El-Hawary, "Interior point methods application in optimum operational scheduling of electric power systems," in IET Generation, Transmission \& Distribution, vol. 3, no. 11, pp. 1020-1029, 2009, doi: 10.1049/iet-gtd.2008.0573.

[18] Youssef A. Mobarak, Nithiyananthan Kannan, "Vertically integrated utility power system structures for Egyptian scenario and electricity act," Jour of Adv Research in Dynamical \& Control Systems, vol. 11, no. 07-Special Issue, pp. 766-772, 2019.

[19] N. Kannan, S. Thomas. Y. Mobarak and F. Alharbi, "Enhanced data communication models for real-time power system monitoring in a distributed platform," Transactions on Emerging Telecommunications Technologies, art. no. e3864, 2020.

[20] N. Kannan, S. Thomas. Y. Mobarak and F. Alharbi, "Application of cloud computing for economic load dispatch and unit commitment computations of the power system network," Computational Vision and Bio-Inspired Computing, 1108 AISC, pp. 1179-1189, 2020.

[21] A. Farag, S. Al-Baiyat and T. C. Cheng, "Economic load dispatch multiobjective optimization procedures using linear programming techniques," in IEEE Transactions on Power Systems, vol. 10, no. 2, pp. 731-738, 1995, doi: 10.1109/59.387910.

[22] R. Habachi, et al., "Economic and emission dispatch using cuckoo search algorithm," International Journal of Electrical and Computer Engineering, vol. 9, no. 5, pp. 3384-3390, 2019.

[23] L. S. Coelho and V. C. Mariani, "Combining of chaotic differential evolution and quadratic programming for economic dispatch optimization with valve-point effect," in IEEE Transactions on Power Systems, vol. 21, no. 2, pp. 989-996, 2006, doi: 10.1109/TPWRS.2006.873410.

[24] Vahid Hosseinnezhad, Mansour Rafiee, Mohammad Ahmadian and Mohammad Taghi Ameli, "Species-based Quantum Particle Swarm Optimization for economic load dispatch," International Journal of Electrical Power and Energy Systems, vol. 63, pp. 311-322, 2014.

[25] S. C. Mohd Nasir, et al., "Multistage artificial immune system for static VAR compensator planning," Indonesian Journal of Electrical Engineering and Computer Science, vol. 14, no. 1, pp. 346-352, 2019.

[26] Youssef A. Mobarak, A. M. Hemeida, A. El-Bahnasawy, and Mohamed M. Hamada, Nithiyananthan Kannan, "Voltage and Frequency based Load Dependent Analysis Model for Egyptian Power System Network," Jour of Adv Research in Dynamical \& Control Systems, vol. 11, 06-Special Issue, pp. 971-978, 2019.

[27] Á. Lorca and X. A. Sun, "Adaptive Robust Optimization With Dynamic Uncertainty Sets for Multi-Period Economic Dispatch Under Significant Wind," in IEEE Transactions on Power Systems, vol. 30, no. 4, pp. 17021713, 2015, doi: 10.1109/TPWRS.2014.2357714. 